Revista Brasileira de Agricultura Irrigada v.11, nº.7, p. 2040 - 2051, 2017

ISSN 1982-7679 (On-line)

Fortaleza, CE, INOVAGRI - http://www.inovagri.org.br

DOI: $10.7127 /$ rbai.v11n700681

Protocolo 681.17 - 14/05/2017 Aprovado em 26/07/2017

\title{
DETERMINAÇÃO DO COEFICIENTE DE CULTIVO DA CULTURA DO PIMENTÃO (Capsicum anuum) POR MEIO DO LISÍMETRO DE DRENAGEM
}

\author{
Paulo Ferreira da Silva ${ }^{1}$, Cinara Bernardo da Silva ${ }^{2}$, Daniella Pereira dos Santos ${ }^{3}$, Célia Silva \\ dos Santos ${ }^{4}$, Márcio Aurélio Lins dos Santos ${ }^{5}$, Julianna Catonio da Silva ${ }^{6}$
}

\begin{abstract}
RESUMO
Objetivou-se com este trabalho instalar e operar lisímetros de drenagem para determinar o coeficiente de cultivo $(\mathrm{Kc})$ da cultura do pimentão na região Agreste do Estado de Alagoas. O experimento foi conduzido em uma área experimental da Universidade Federal de Alagoas, Campus de Arapiraca-AL. Foram instalados três lisímetros de drenagem em uma área com 4,20 x 1,50 m de comprimento e largura, respectivamente, onde foi instalado um sistema de irrigação por gotejamento. Para estimativa da evapotranspiração de referência (ETo) foram utilizados dois métodos: Hargreaves-Samani e Penman-Monteith. Para o método de PenmanMontheith os valores médio, máximo e mínimo da ETo foram de 4,25; 6,12 e 1,38 mm.d ${ }^{-1}$, respectivamente. No método de Hargreaves-Samani, a ETo teve valores médio, máximo e

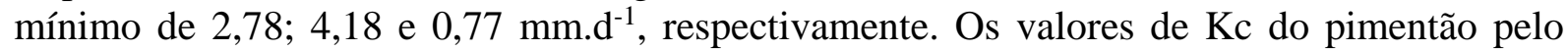
método de Hargreaves-Samani, foram correspondentes a 1,05 e 1,41 nas fases II e III, respectivamente. Pelo método de Penman Montheith foi de 0,81 e 1,05 para as fase II e III, respectivamente. Os lisímetros de drenagem permitiram determinar o Kc específico para a cultura do pimentão, demonstrando ser uma ferramenta eficiente no manejo da irrigação.
\end{abstract}

Palavras-chave: balanço hídrico, evapotranspiração, manejo de irrigação

\section{DETERMINATION OF THE CROP COEFFICIENT OF SWEET PEPPER (Capsicum anuUm) BY MEANS OF DRAIN LYSIMETER}

\footnotetext{
ABSTRACT

The objective of the work installed and operate drainage lysimeters to determine the crop coefficient $(\mathrm{Kc})$ of the sweet pepper crop in the Agreste region of the state of Alagoas. The

${ }^{1}$ Doutorando em Irrigação e Drenagem, Faculdade de Ciências Agronômicas - UNESP, Rua José Barbosa de Barros, nº 1780, CEP: 18.610-307 Botucatu-SP, e-mail: pauloagrom@gmail.com

2 Mestranda em Agricultura e Ambiente, Universidade Federal de Alagoas/Campus Arapiraca, Arapiraca-AL, e-mail: cinara_cbs@hotmail.com

3 Doutoranda em Engenharia Agrícola, Universidade Federal Rural de Pernambuco, Recife-PE, e-mail: daniellapsantos@hotmail.com

${ }^{4}$ Doutoranda em Engenharia Agrícola, Universidade Federal Rural de Pernambuco, Recife-PE, e-mail: celia@agro.eng.br

${ }^{5}$ Professor Adjunto IV, Universidade Federal de Alagoas/Campus Arapiraca, Arapiraca-AL, e-mail: mal.santo@hotmail.com

${ }^{6}$ Mestranda em Agricultura e Ambiente, Universidade Federal de Alagoas/Campus Arapiraca, Arapiraca-AL, e-mail: julianna_cds@hotmail.com
} 
experiment was conducted in an experimental area of the Federal University of Alagoas, Campus of Arapiraca-AL. Three drainage lysimeters were installed in an area of $4.20 \times 1.50$ $\mathrm{m}$ in length and width, respectively, where a drip irrigation system was installed. To estimate the reference evapotranspiration (ETo), two methods were used: Hargreaves-Samani and Penman-Monteith. For the Penman-Montheith method the mean, maximum and minimum values of ETo were 4.25; 6.12 and $1.38 \mathrm{~mm} . \mathrm{d}^{-1}$, respectively. In the Hargreaves-Samani method, ETo had mean, maximum and minimum values of $2.78 ; 4.18$ and $0.77 \mathrm{~mm}$. $\mathrm{d}^{-1}$, respectively. The Kc values of the sweet pepper by the Hargreaves-Samani method corresponded to 1.05 and 1.41 in phases II and III, respectively. By the Penman method Montheith was 0.81 and 1.05 for phase II and III, respectively. The drainage lysimeters allowed to determine the specific Kc for the sweet pepper crop, proving to be an efficient tool in irrigation management.

Keyword: hydric balance, evapotranspiration, irrigation management

\section{INTRODUÇÃO}

O pimentão (Capsicum annuum L.) do ponto de vista econômico está entre as dez hortaliças mais importantes do mercado brasileiro (CAMPOS et al., 2008). O pimentão é uma cultura que apresenta uma diversidade de variedades, sendo muito utilizadas as variedades híbridas, que em virtude do elevado potencial produtivo e resistência a determinadas pragas ou doenças, tem atraído cada vez mais o interesse de produtores em cultivá-las na região Agreste do Estado de Alagoas. Atualmente, verifica-se que tem crescido o interesse comercial pelas cultivares de frutos vermelhos, pois, seus frutos possuem alto teor de vitamina C e são utilizados na fabricação de condimentos, conservas e molhos (CARVALHO et al., 2011).

A falta de conhecimento sobre a necessidade hídrica da cultura e adoção de manejo inadequado de irrigação faz com que os agricultores normalmente utilizem quantidades excedentes de água. Lima et al. (2012) relataram que o excesso de umidade pode causar danos à cultura, como apodrecimento de raiz e colo da planta, além disso, se cultivada em campo pode ocasionar a ocorrência de doenças fúngicas na parte aérea da planta e nos frutos.

A demanda hídrica das plantas é diferenciada de acordo com a sua fase fenológica, necessitando de um coeficiente de cultivo (Kc) específico para cada uma das fases. O Kc pode ser determinado através da utilização de lisímetros que segundo Carvalho et al. (2013), lisímetros são estruturas destinadas a medir de maneira extremamente confiável eventos de precipitação, evaporação e drenagem.

Conhecer a demanda hídrica em cada fase da cultura é de suma importância para um bom manejo da irrigação, principalmente nas fases II e III que há um consumo maior de água pelas culturas. Carvalho et al. (2016) trabalhando com diferentes tensões de água no solo aplicada em duas fases fenológicas do pimentão constataram que a produtividade comercial obtida com estresse na fase vegetativa foi, em média, maior do que a produtividade comercial obtida com estresse na fase reprodutiva. Sabendo qual o Kc ideal para a cultura nessas fases, torna-se eficiente o fornecimento de água por meio da irrigação evitando 0 estresse hídrico tanto pelo excesso quanto pela redução da lâmina de irrigação.

Assim, objetivou-se com este trabalho instalar e operar três lisímetros de drenagem para determinar o coeficiente de cultivo (Kc) específico para a cultura do pimentão cultivado na região Agreste do Estado de Alagoas, para ser utilizado pelos agricultores locais, tornando possível a adoção do manejo correto da irrigação, diminuindo o uso excessivo de água e tornando possível alcançar a potencialização da produtividade da cultura. 


\section{MATERIAL E MÉTODOS}

O experimento foi conduzido em uma área experimental do Grupo Irriga do Curso de Agronomia do Campus de Arapiraca da Universidade Federal de Alagoas, localizada no município de Arapiraca (AL), com latitude $09^{\circ} 45^{\prime} 09^{\prime \prime} \mathrm{S}$, longitude $36^{\circ} 39^{\prime} 40^{\prime \prime} \mathrm{W}$ e altitude $325 \mathrm{~m}$, situada na região Agreste do Estado de Alagoas localizada a uma distância de 130 km da capital Maceió (AL).

O solo da área de estudo foi classificado como Latossolo amarelo vermelho distrófico (EMBRAPA, 2013). Segundo a classificação de Koppen, o clima local é do tipo 'As', isto é, clima tropical com verão seco. De acordo com Xavier e Dornellas (2010), a estação chuvosa inicia no mês de maio e se estende até a primeira quinzena de agosto, com precipitação pluvial média de $854 \mathrm{~mm}$.ano ${ }^{-1}$, sendo os meses de maio a julho os mais chuvosos e setembro a dezembro os mais secos.

Para a instalação dos lisímetros de drenagem, foi necessário inicialmente fazer a escavação das trincheiras manualmente com dimensões de 0,5 x 3,0 x 0,80 m de largura, comprimento e de profundidade, respectivamente. Durante a escavação, foram separadas 4 camadas de solo definidas e identificadas na ordem de 0 - 0,20;0,20 0,$40 ; 0,40-0,60$ e $0,60-0,80 \mathrm{~m}$ do solo, que posteriormente foram utilizadas no preenchimento dos lisímetros, mantendo assim a mesma sequência original do perfil do solo.

A trincheira utilizada para armazenar a água proveniente da drenagem dos lisímetros, não teve suas camadas de solo separadas, uma vez que esta permaneceu aberta para possibilitar o acesso às coletas diárias dos volumes drenados. Esta trincheira teve dimensões de $0,8 \mathrm{x}$ $3,0 \mathrm{~m}$ de largura e comprimento, com profundidade de $1,5 \mathrm{~m}$, para colocar os recipientes coletores da água drenada posicionados a uma pequena declividade no sentido do dreno para facilitar a caída de água drenada dos lisímetros (Figura 1).

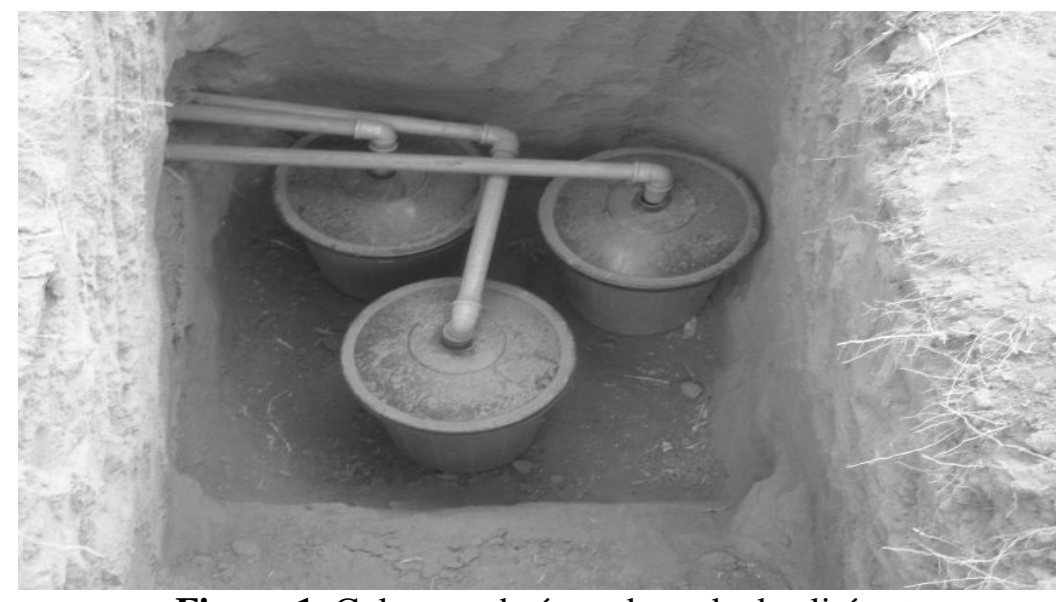

Figura 1. Coletores da água drenada dos lisímetros.

Os lisímetros tiveram formato circular, e constituídos de bombonas (tonéis plásticos) com dimensões de 0,425 x $0,80 \mathrm{~m}$ de diâmetro e profundidade, respectivamente. $\mathrm{O}$ sistema de drenagem dos lisímetros foi constituído de tubos de polietileno de $32 \mathrm{~mm}$ de diâmetro, disposto ao longo do cilindro, sendo instalados na base inferior das bombonas (Figura 2). Na saída interna do dreno, na base inferior do lisímetro foi colocada uma tela flexível de náilon para evitar a entrada de sedimentos na tubulação. 


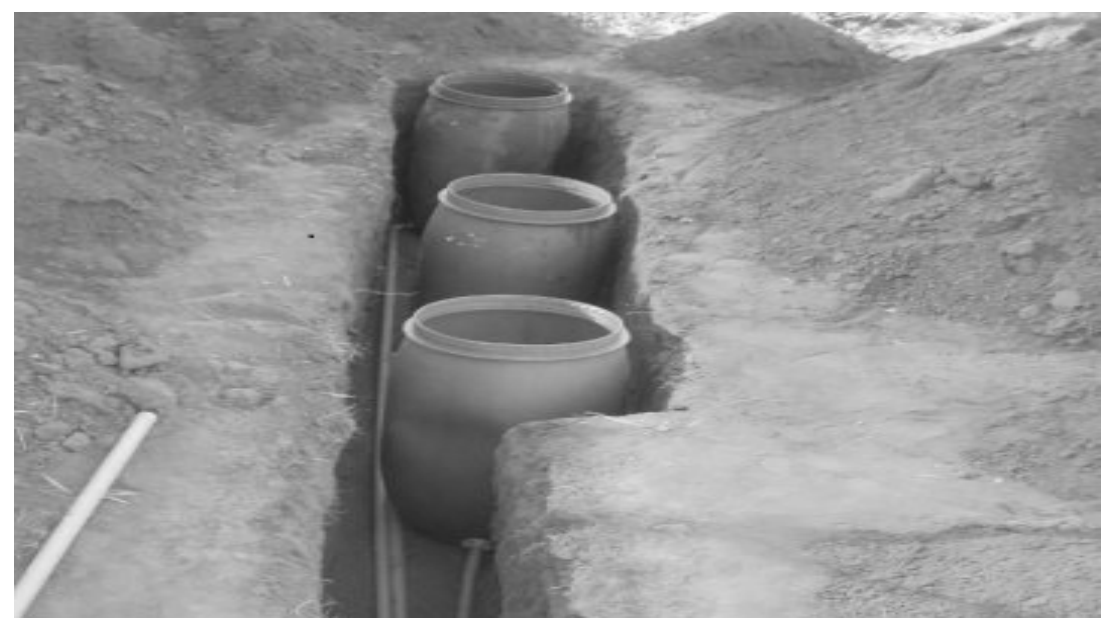

Figura 2. Bombonas (tonéis) utilizados como lisímetros e o sistema de tubulação de drenagem para os coletores.

O enchimento dos lisímetros iniciou com uma camada de $0,10 \mathrm{~m}$ de brita zero para facilitar a drenagem da água, mais $0,10 \mathrm{~m}$ de solo da quarta camada correspondente à profundidade de 0,60 a $0,80 \mathrm{~m}$ do solo, sendo as demais camadas de $0,20 \mathrm{~m}$ adicionadas na ordem inversa da escavação.

A tubulação de $32 \mathrm{~mm}$ foi colocada para interligar o sistema de drenagem dos lisímetros a unidade de coletora de água drenada. Para cada camada de solo colocada nos lisímetros foi feito uma pequena compactação com o auxilio de uma enxada apenas para acomodar o solo no recipiente, sendo repetido este procedimento em todos os lisímetros e com o solo seco para não causar compactação indesejada ao solo.

Foram instalados três lisímetros de drenagem em uma área experimental com dimensões de 4,20 x 1,50 m de comprimento e largura, respectivamente, correspondendo a uma área total de $6,3 \mathrm{~m}^{2}$. Dimensionou-se a área para 3 linhas contendo 7 plantas, com espaçamento adotado de $0,75 \mathrm{~m}$ entre as linhas de plantio e 0,60 m entre plantas, formando uma população total de 21 plantas. Instalou-se os lisímetros na $2^{\text {a }}$ linha que corresponde a linha central da área, dimensionados para que as plantas mantivessem os mesmos espaçamentos tanto nas linhas dos lisímetros quanto para as linhas das extremidades.

Realizou-se o transplante das plântulas de pimentão no dia 16 de fevereiro de 2013, e a variedade escolhida foi a All Big adquirida de um viveiro comercial localizado no município de Arapiraca, sendo transplantadas aos 23 dias após o plantio (DAP), quando estas atingiram altura variando entre 10 a 12 $\mathrm{cm}$. O solo havia sido previamente adubado com $1,7 \mathrm{~kg}$ por cova de esterco bovino, incorporado na área quinze dias antes do transplante das plântulas.

Foi instalado um sistema de irrigação localizada, utilizando-se gotejadores autocompensante modelo GA-4 do fabricante Agrojet com vazão de $4 \mathrm{~L} \cdot \mathrm{h}^{-1}$ a uma pressão de 10 mca (metro de coluna d'água). Após a instalação do sistema, realizou-se um ensaio de uniformidade do sistema através do método do coeficiente de uniformidade de distribuição (CUD) proposto por Keller \& Karmeli (1975), cuja vazão encontrada foi de 1,5 L.h ${ }^{-1}$, a uma pressão de 1 mca. Foi colocado um gotejador em cada lisímetro sendo instalado próximo ao caule das plântulas (Figura 3). A distribuição da água foi por gravidade saindo de um reservatório com capacidade volumétrica de 18 litros com distribuição de água direcionada para cada planta dos lisímetros. 


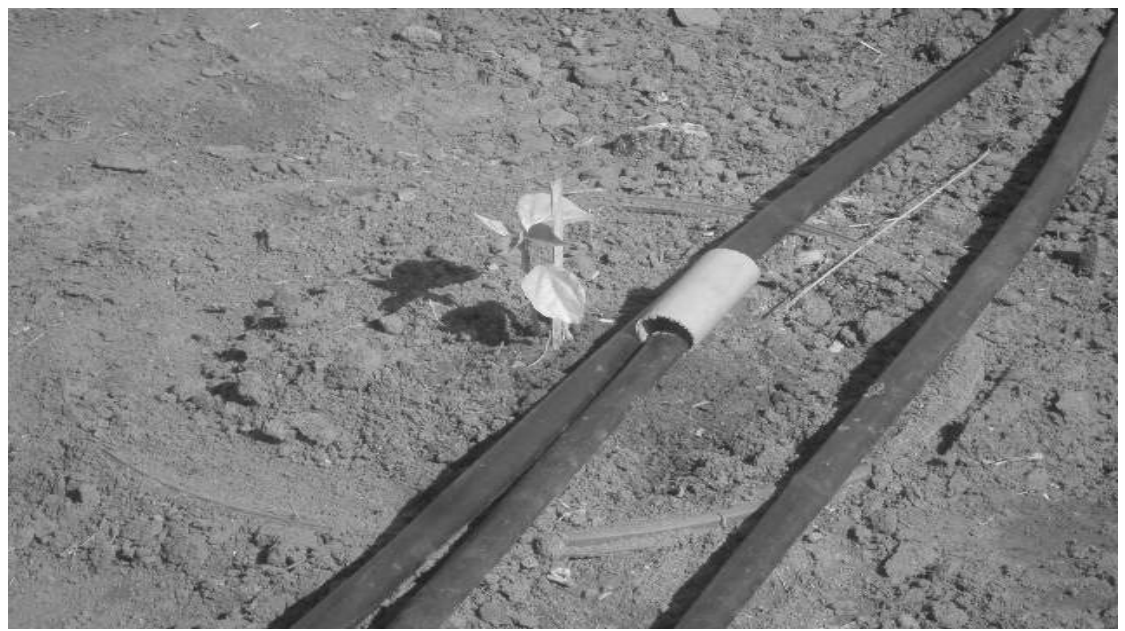

Figura 3. Plântula de pimentão no centro do lisímetro com gotejador instalado na fita próximo ao caule.

As plantas das linhas das extremidades foram irrigadas através de dois reservatórios distintos, sendo que um destes reservatórios distribuía água para uma quantidade maior de plantas, com uma saída de água simultaneamente para duas linhas (Figura 4). Dessa forma, além das 7 plantas contidas na linha de uma das extremidades, outras 4 plantas contidas na linha central que intercalavam os lisímetros também eram irrigadas. Os reservatórios foram instalados e organizados em uma bancada contendo 5 reservatórios, sendo os dois das extremidades para irrigar as plantas das linhas laterais, e os três reservatórios centrais utilizados para irrigar apenas as plantas dos lisímetros.

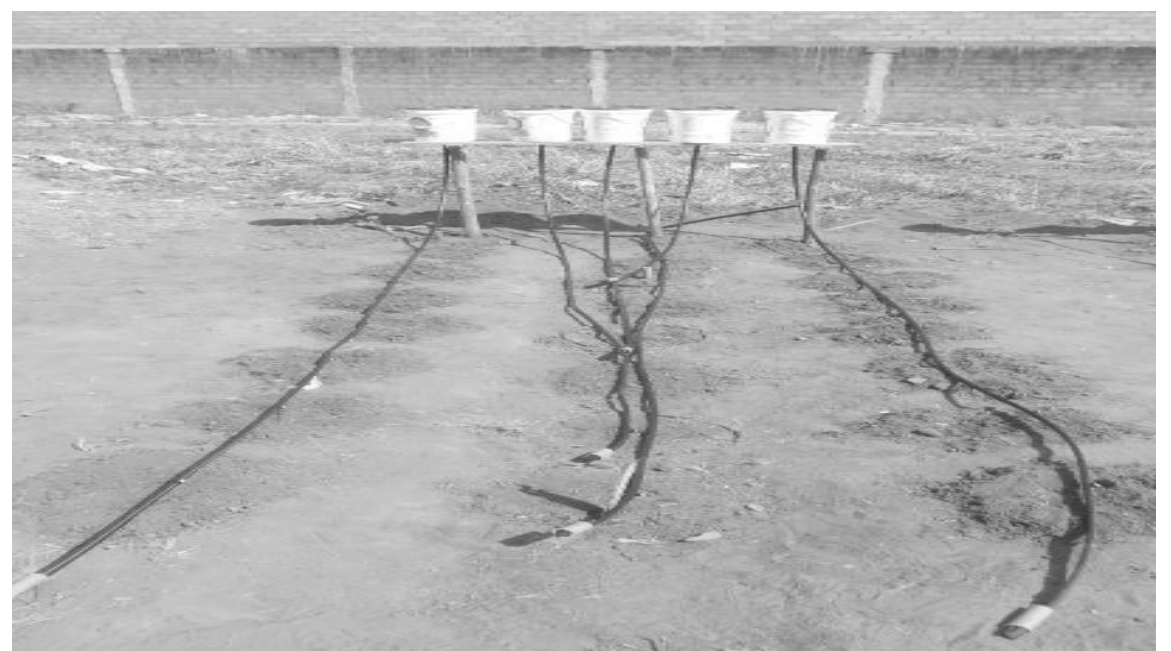

Figura 4. Bancada contendo os reservatórios e a distribuição do sistema de irrigação na área.

A coleta dos dados iniciou 3 dias após o transplante, quando as plântulas já estavam estabelecidas no ambiente. A mensuração da água coletada dos drenos foi realizada com o auxílio de proveta graduada com capacidade para um litro, em frequência diária a cada 24 horas, tendo início sempre no mesmo horário por volta de 8 horas e término às 9 horas da manhã. Após quantificar a água drenada, determinou-se a lâmina diária de irrigação e verificação da funcionalidade do sistema de irrigação.

Para estimativa da evapotranspiração de referência (ETo) foram coletados os dados fornecidos da estação meteorológica do Instituto Nacional de Meteorologia (INMET) localizado no bairro Batingas a $8 \mathrm{~km}$ do local do experimento na cidade de Arapiraca os quais foram utilizados para comparar com dois métodos meteorológicos: HargreavesSamani e Penman-Monteith.

O método de Hargreaves-Samani, para 
estimativa da ETo diária, em $\mathrm{mm}^{-} \mathrm{d}^{-}$ 1 , pode ser apresentado por Pereira et al.

$$
\text { ETo }=0,0023 \mathrm{Rn}(\mathrm{T}+17,8) \sqrt{\mathrm{Tmax}-\mathrm{Tmin}}
$$

em que:

ETo = evapotranspiração de referência, $\mathrm{mm} \mathrm{d}^{-}$ 1

$\mathrm{Rn}=$ saldo de radiação, $\mathrm{MJ} \cdot \mathrm{m}^{-2} \cdot \mathrm{d}^{-1}$

$\mathrm{T}=$ temperatura média diária, ${ }^{\circ} \mathrm{C}$
Tmax $=$ temperatura máxima, ${ }^{\circ} \mathrm{C}$

Tmin = temperatura mínima, ${ }^{\circ} \mathrm{C}$

A determinação de $\mathrm{Rn}$ foi obtido pela Equação 2.

$$
\mathrm{Rn}=37,586 \mathrm{dr}_{\mathrm{r}}\left(\omega_{\mathrm{s}} \operatorname{sen} \varphi \operatorname{sen} \delta_{\mathrm{s}}+\cos \delta_{\mathrm{s}} \operatorname{sen} \omega_{\mathrm{s}}\right)
$$

em que:

$\mathrm{d}_{\mathrm{r}}=$ distância relativa Terra-Sol [rad]

$\omega_{\mathrm{s}}=$ ângulo horário do pôr-do-sol [rad]

$\varphi=$ latitude do lugar [rad]

$\delta_{\mathrm{s}}=$ declinação solar [rad]
O modelo utilizado para ETo pelo método de Penman - Monteith, foi descrito por Allen et al. (1998) utilizando a seguinte Equação

$$
\text { ETo }=\frac{\delta}{\delta+\gamma\left(1+\frac{\mathrm{r}_{\mathrm{c}}}{\mathrm{ra}_{\mathrm{a}}}\right)} \frac{(\mathrm{Rn}-\mathrm{G})}{\lambda}+\frac{\gamma}{\delta+\gamma\left(1+\frac{\mathrm{r}_{\mathrm{c}}}{\mathrm{ra}_{\mathrm{a}}}\right)} \frac{900}{\mathrm{~T}+273,15} \mathrm{U}_{2} \mathrm{DPV}
$$

em que:

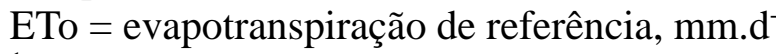
1

$\delta=$ declividade da curva de pressão de vapor de saturação, $\mathrm{kPa} .{ }^{\circ} \mathrm{C}^{-1}$

$\lambda=$ calor latente de evaporação, ${\mathrm{MJ} . \mathrm{kg}^{-1}}^{-1}$

$\mathrm{rc}_{\mathrm{c}}=$ resistência do dossel da planta, $\mathrm{s} . \mathrm{m}^{-1}$

$\mathrm{ra}=$ resistência aerodinâmica, s.m $^{-1}$

$\mathrm{Rn}=$ saldo de radiação à superfície, $\mathrm{kJ} \cdot \mathrm{m}^{-2} \cdot \mathrm{s}^{-1}$

$\mathrm{G}=$ fluxo de calor no solo, $\mathrm{kJ} \cdot \mathrm{m}^{-2} \cdot \mathrm{s}^{-1}$

$\gamma=$ constante psicrométrica, $\mathrm{kPa} .{ }^{\circ} \mathrm{C}^{-1}$

$\mathrm{T}=$ temperatura média do ar, ${ }^{\circ} \mathrm{C}$

$\mathrm{U}_{2}=$ velocidade do vento a $2 \mathrm{~m}$ de altura, $\mathrm{m} . \mathrm{s}^{-}$ 1

$\mathrm{DPV}=$ déficit de pressão de vapor, $\mathrm{kPa}$

900 = fator de transformação de unidades, $\mathrm{kJ} \cdot \mathrm{kg}^{-1} \cdot \mathrm{K}^{-1}$

A lâmina de irrigação aplicada diariamente nos lisímetros foi calculada conforme descrito por Santos et al. (2016), do qual foram estimadas com base no balanço hídrico do lisímetro de drenagem e $50 \%$ do Kc, para manter o lisímetro em drenagem frequente, sendo o mesmo de acordo com sua fase fenológica segundo a Equação 4.

$$
\mathrm{La}=(\mathrm{I}-\mathrm{D}) \cdot(\mathrm{FC} \cdot \mathrm{Kc})+\mathrm{D}
$$

em que:

La = lâmina aplicada, mm;

$\mathrm{I}$ = irrigação, mm;

$\mathrm{D}=$ volume drenado, $\mathrm{mm}$;

Fc = fator de correção, $50 \%$ do Kc;

Kc $=$ coeficiente de cultura do pimentão variando de acordo com a fase fenológica, adimensional.

A evapotranspiração da cultura (ETc) foi obtida através de coletas realizadas diariamente nos drenos dos lisímetros. Uma vez que o balanço de água foi determinado entre duas ocorrências sucessivas de drenagem, a variação da umidade no solo $(\Delta \mathrm{U})$ se tornava desprezível, pois, em seguida ao término da drenagem, o conteúdo de água no solo em cada lisímetro retornava à capacidade de campo, e a ETc considerada corresponde a média dos dados ocorridos nos intervalos de tempo entre as drenagens de acordo com (ABOUKHALED et al., 1982) que estabelece a seguinte Equação 5: 


$$
\mathrm{ETc}=\mathrm{P}+\mathrm{I}-\mathrm{D}
$$

em que:

ETc = Evapotranspiração da cultura, mm

$\mathrm{P}=$ Precipitação pluviométrica, $\mathrm{mm}$

I = Lâmina de água aplica por irrigação, mm

$\mathrm{D}$ = Água drenada do lisímetro, mm

A evapotranspiração da cultura (ETc) obtida foi para um período de 7 dias, a qual foi convertida em evapotranspiração diária $\left(\mathrm{mm} \cdot \mathrm{d}^{-1}\right)$ sendo assim quantificado a perda de água no sistema.

A razão entre evapotranspiração da cultura (Etc) e a evapotranspiração de referência (ETo) é denominado coeficiente de cultivo (Kc). A partir da ETo e dos valores de ETc, foram determinados os coeficientes de cultivo para cada balanço hídrico, nas condições experimentais, pela relação entre a ETc obtida pelo balanço de água nos lisímetros, e a ETo de Penman-Monteith e Hargreaves-Samani expresso na seguinte Equação 6:

$$
\mathrm{Kc}=\frac{\mathrm{ETc}}{\mathrm{ETo}}
$$

Em que:

Kc = coeficiente de cultivo, adimensional ETc = evapotranspiração da cultura, mm.d ${ }^{-1}$ ETo = evapotranspiração de referência, mm.d ${ }^{-}$ 1

Conceição et al. (2012) afirmam que o Kc varia de acordo com sua fase fenológica, do qual eles apresentam 4 fases distintas:

Fase I. Representa o estabelecimento inicial da cultura que vai da semeadura até à germinação.

Fase II. Caracteriza o desenvolvimento vegetativo que inicia da germinação até o florescimento.

Fase III. Período reprodutivo inicia no florescimento e termina com o enchimento dos grãos ou formação de fruto.

Fase IV. Quando ocorre a maturação.

A distribuição espacial de cada fase de coeficiente de cultivo (Kc) para os períodos inicial, desenvolvimento da cultura, intermediário e final tiveram durações de 25, 35, 45 e 15 dias, respectivamente. De acordo com a FAO 33, os valores para o Kc recomendado para a cultura do pimentão nas fases fenológicas I, II, III e IV são 0,$4 ; 0,75 ; 1,10$ e 0,8 , respectivamente.

\section{RESULTADOS E DISCUSSÃO}

Observou-se que os valores da evapotranspiração de referência pelo método de Penman-Montheith (ETo_PM) e a evapotranspiração de referência pelo método de Hargreaves-Samani (ETo_HS) apresentaram comportamento semelhantes durante todo o período, com o valor médio de 4,25 mm.d ${ }^{-1}$, com valor mínimo de $1,38 \mathrm{~mm}$ no dia 04/03 aos 43 DAP e máximo de 6,12 mm no dia 12/03 aos 51 DAP para o método de Penman-Montheith. No método de Hargreaves-Samani, para a evapotranspiração de referência, observou-se o valor médio de 2,78 mm.d $\mathrm{d}^{-1}$, com valor mínimo de 0,77 mm no dia 04/03 aos 43 DAP e máximo de 4,18 mm no dia 12/03 aos 51 DAP (Figura 5). 


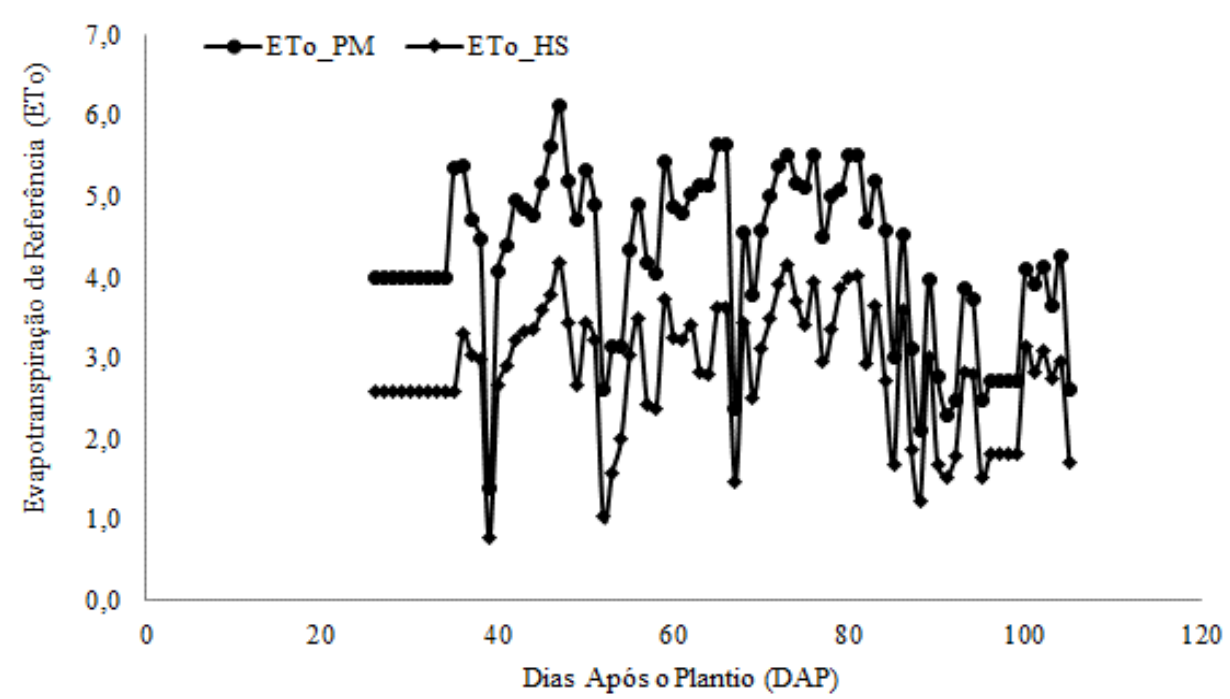

Figura 5. Evapotranspiração de referência (ETo) estimado pelos métodos de Penman Monteith (ETo_PM) e Hargreaves-Samani (ETo_HS) durante o ciclo da cultura do pimentão.

As temperaturas máximas e mínimas ocorridas simultaneamente para ambos os métodos é justificada pelo saldo de radiação para o dia 04/03 que foi de 3,15 MJ.m ${ }^{-1}$ com temperatura máxima de $27,7^{\circ} \mathrm{C}$, a menor registrada para todo o período. Os valores obtidos para a radiação no dia 12/03 foi de 10,92 MJ.m ${ }^{-1}$, com temperaturas na ordem de $35,9^{\circ} \mathrm{C}$, sendo esta a maior temperatura registrada no período.
A ETc representando o consumo de água diário pela planta passaram a ser analisados a partir de 25 dias após o plantio em virtude das plântulas terem sido adquiridas de um viveiro da região como é feito pelos produtores. Os níveis mais elevados da evapotranspiração da cultura tiveram picos representativos nas fases inicial, intermediária e final do período analisado (Figura

$6)$.

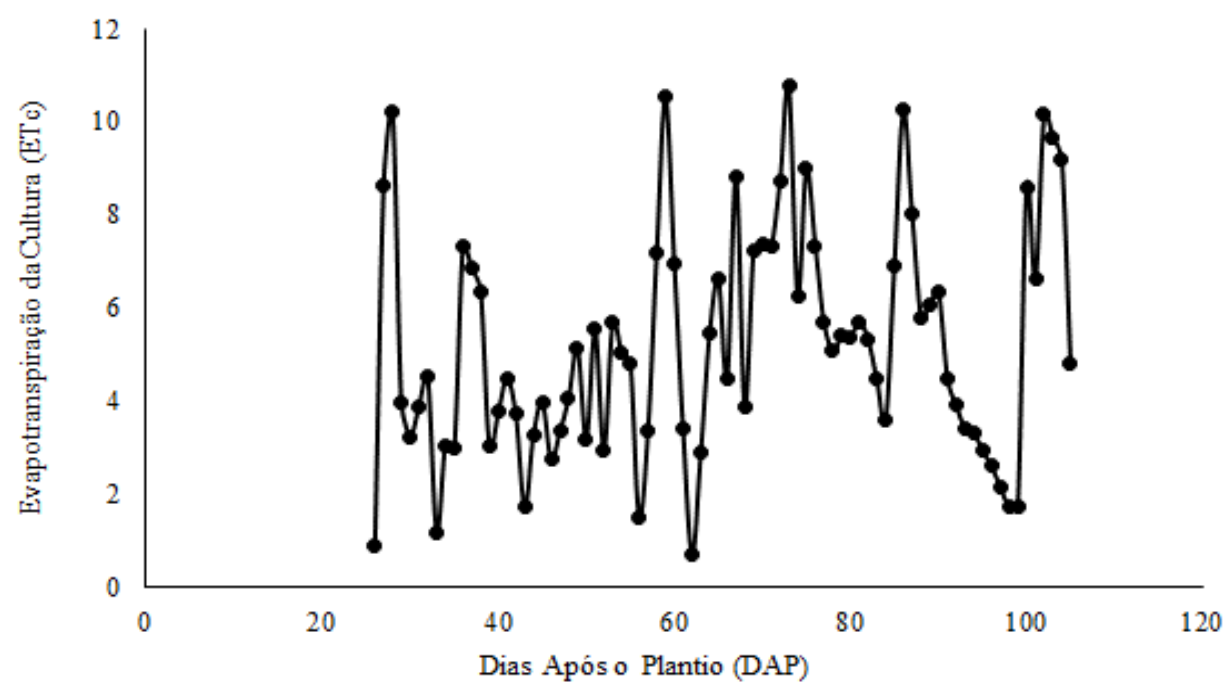

Figura 6. Evapotranspiração da cultura (ETc) diária expressando o consumo de água pela cultura no período de 16 de fevereiro a 9 de maio de 2013.

As maiores ocorrências de evapotranspiração da cultura foi na fase de floração e frutificação da cultura, atingindo o nível máximo de 10,78 mm.d $\mathrm{d}^{-1}$. Estudando a cultivar de pimentão Yolo em casa-de- vegetação, Lima et al. (2006) verificaram a ETc média diária de $10,7 \mathrm{~mm} . \mathrm{d}^{-1}$, embora este resultado tenha sido encontrado em ambiente protegido.

Os valores de coeficientes de cultivo 
(Kc) para a cultura do pimentão neste trabalho foram bastante semelhantes aos valores de Kc adotados pela FAO-33. De acordo com a metodologia apresentada, a determinação da evapotranspiração da cultura (ETc) por meio das diferenças do volume de água adicionado nos lisímetros e dos volumes observados na drenagem, representam o consumo de água diário pela planta.

O volume de água consumido pela cultura do pimentão no período de execução do experimento foi de $530 \mathrm{~mm}$, resultando em um consumo médio de $6,6 \mathrm{~mm} \cdot \mathrm{d}^{-1}$. Resultados semelhantes foram observados por Chaves et al. (2008) em trabalho realizado entre os meses de setembro a janeiro de 2004 no município de Pentecoste, Ceará, com consumo médio de água de $7,3 \mathrm{~mm} . \mathrm{d}^{-1}$.

Os menores valores encontrados para ETc durante o período do experimento foi possivelmente em virtude da ocorrência de chuva no período, incidindo em alterações no balanço hídrico dos lisímetros. Já o coeficiente de cultivo foi determinado através de dois métodos indiretos de estimativa de evapotranspiração de referência, o método de Hargreaves-Samani com valores representados pela Figura 7, e o método de Penman Montheith sugerido pela FAO 56 com valores representados pela Figura 8.

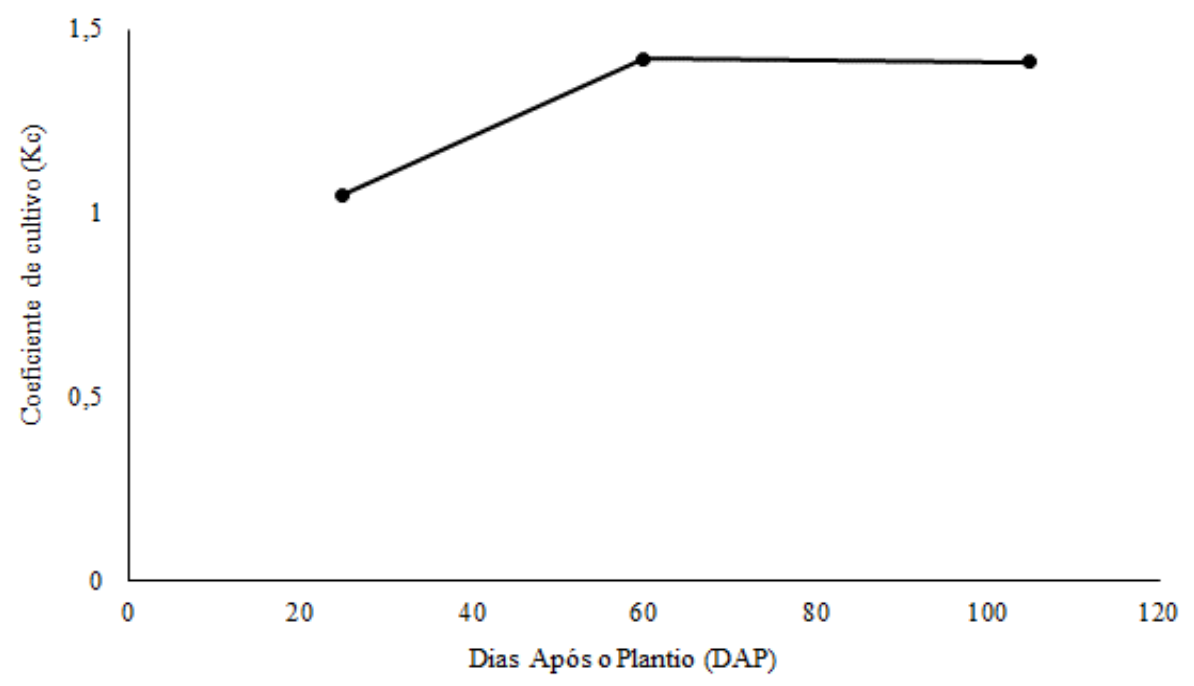

Figura 7. Coeficiente de cultivo (Kc) do pimentão All Big, pelo método de Hargreaves-Samani.

O coeficiente de cultivo do pimentão pelo método de Hargreaves-Samani, tiveram valores médios de Kc correspondentes a 1,05 e 1,41 nas fases II e III, respectivamente. Os valores subestimados da ETo por este método proporcionaram a superestimativa dos valores de Kc quando comparados ao método de Penman Montheith. Esse resultado possivelmente está associado ao número de variáveis utilizadas pelo método, uma vez, que o mesmo considera apenas a temperatura do ar e a radiação no topo da atmosfera na sua estimativa (DA SILVA et al., 2015).

Os valores de Kc pelo método de estimativa de Penman Montheith encontrados nesta pesquisa foram de 0,81 para a fase II e 1,05 para a fase III (Figura 8). Resultados semelhantes de Kc para a cultura do pimetão estão sendo recomendados pela FAO 33 que para as respectivas fases, os valores correspondem a 0,75 1,1 . 


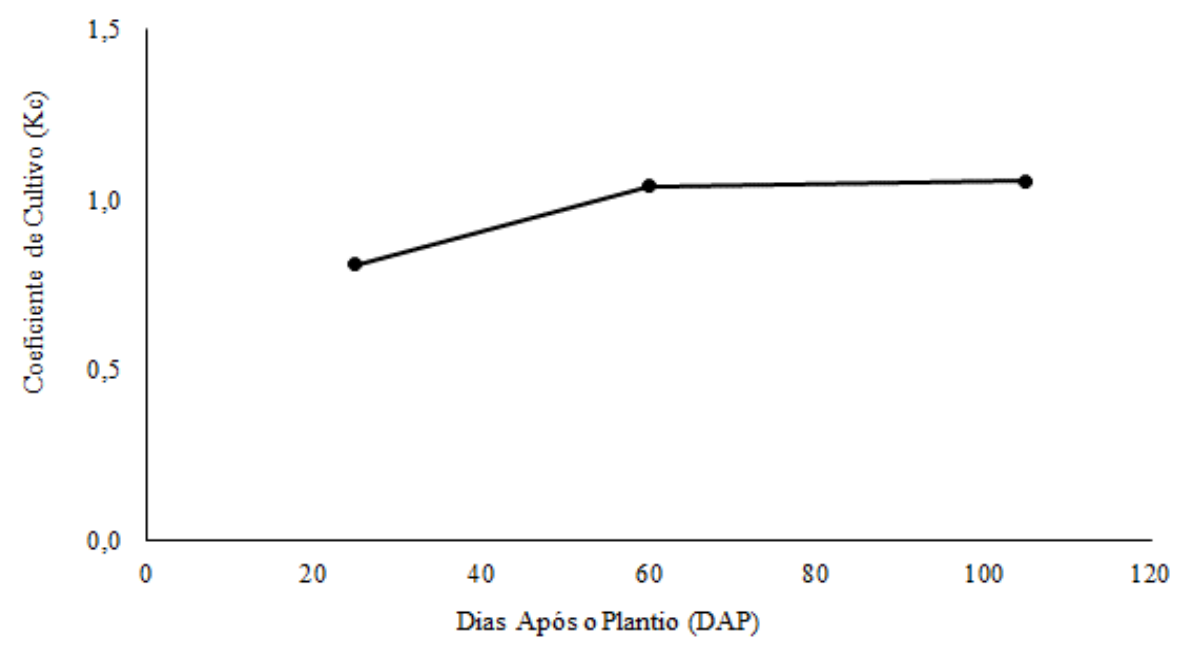

Figura 8. Coeficiente de cultivo do pimentão All Big, pelo método de Penman Montheith.

Valores inferiores de Kc obtidos por Albuquerque et al. (2012) que foram 0,5 e 0,46 para a fase II e 0,63 e 0,65 para a fase III, utilizando doses de potássio (80 e 120 kg K2O $\left.\mathrm{ha}^{-1}\right)$, respectivamente. Os autores supracitados mencionam que seus valores de Kc foram distintos aos da FAO 33, e que essa constatação reforça a necessidade de ajustes de coeficientes de cultivo para cada região específica e condições edafoclimáticas.

Confirmando as informações dos autores supracitados, Sharma et al. (2017) encontraram valores de Kc de 1,05 no Novo México no ciclo de pimentão cultivado no ano de 2011, e Kc de até 1,56 no cultivo de 2013. Essa diferença nos valores de Kc entre um ano e outro ocorreu segundo os autores, pelo fato do pimentão ter sido cultivado em períodos diferentes do ano, tornando importante a determinação do Kc para cada ciclo da cultura em diferentes estações do ano. Os valores encontrados no presente trabalho foram semelhantes aos de Souza et al. (2011), que encontraram o valor de Kc de 1,05 para a fase intermediária no sistema de plantio direto.

\section{CONCLUSÕES}

Tendo em vista que as plântulas foram adquiridas de um viveiro comercial no período correspondente a fase I, e com a incidência de dias chuvosos no início da fase IV que acarretou em uma instabilidade no funcionamento dos lisímetros, não foi possível determinar um Kc específico para essas duas fases.

Por meio do lisímetro de drenagem foi possível determinar o consumo de água para a cultura do pimentão sob as condições locais do Agreste de Alagoas.

Os coeficientes de cultivo determinado para a cultura do pimentão pelo método de Penman-Montheith foram confiáveis para as fases fenológicas II e III.

Já os coeficientes de cultivo foram superestimados quando determinados por meio do método de Hargreaves-Samani, sendo recomendada sua utilização apenas para situações que não haja acessibilidade de dados climatológicos completos, ou quando possível ajustar a equação.

\section{REFERÊNCIAS BIBLIOGRÁFICAS}

ABOUKHALED, A.; ALFARO, A.; SMITH, $M$. Lysimeters. FAO, (FAO. Irrigation and Drainage Paper 39, Rome, 1982. 68 p.

ALBUQUERQUE, F. D. S.; SILVA, E. F. F.; ALBUQUERQUE FILHO, J. A. C.; LIMA, G. S. Necessidade Hídrica e Coeficiente de Cultivo do Pimentão Fertirrigado. Revista Irriga, p. 481-493, 2012.

ALLEN, R. G.; PEREIRA, L. S.; RAES, D.; SMITH, M. FAO Irrigation and drainage paper $\mathbf{N}^{\mathbf{}}$. 56. Rome: Food and Agriculture 
Organization of the United Nations, 1998. $300 \mathrm{p}$.

CAMPOS, V. B.; OLIVEIRA, A. P.; CAVALCANTE, L. F.; PRAZERES, S. S. Rendimento do pimentão submetido ao nitrogênio aplicado via água de irrigação em ambiente protegido. Revista de Biologia e Ciências da Terra, v.8, p.72-79, 2008.

CARVALHO, J. A.; REZENDE, F. C.; AQUINO, R. F.; FREITAS, W. A.; OLIVEIRA, E. C. Análise produtiva e econômica do pimentão-vermelho irrigado com diferentes lâminas, cultivado em ambiente protegido. Revista Brasileira de Engenharia Agrícola e Ambiental, Campina Grande, v.15, p. 569-574, 2011.

CARVALHO, H. P.; MELO, B.; ATARASSI, R. T.; CAMARGO, R.; SILVA, C. R.; MORAES, M. R. B. Desenvolvimento de lisímetros de pesagem na cultura do café. Development weighing lysimeters for coffee culture. Bioscience Journal, v.29, n.6, p. 1750-1760, 2013.

CARVALHO, J. A.; REZENDE, F. C.; OLIVEIRA, E. C.; AQUINO, R. F. Pimentão cultivado em ambiente protegido sob diferentes tensões de água no solo. Engenharia na agricultura, Viçosa - MG, v.23 n.3, p.233-245, maio / junho, 2016.

CHAVES, S. W. P.; AZEVEDO, B. M.; MEDEIROS, J. F.; BEZERRA, F. M. L.; DE MORAIS, N. B. Evapotranspiração e coeficiente de cultivo da pimenteira em lisímetro de drenagem. Revista Ciência Agronômica, v.36, p. 262-267, 2008.

CONCEIÇÃO, M. A. F.; SOUZA, R. T.; ZEOLI, J. D. J. S.; PAULA, M. V. B. Coeficiente de cultura $(\mathrm{kc})$ para videira com e sem cobertura vegetal no solo. Revista Irriga, Botucatu, Edição especial, p. 234-249, 2012.

DA SILVA, M. G.; OLIVEIRA, I. D. S.; DO CARMO, F. F.; LÊDO, E. R. F.; DA SILVA
FILHO, J. A. Estimativa da evapotranspiração de referência pela equação de HargreavesSamani no Estado do Ceará, Brasil/Reference evapotranspiration estimated by HargreavesSamani in the State of Ceará, Brazil. Revista Brasileira de Engenharia de Biossistemas, v. 9, n. 2, p. 132-141, 2015.

EMBRAPA - Empresa Brasileira de Pesquisa Agropecuária. Centro Nacional de Pesquisa de Solos. Sistema brasileiro de classificação de solos. 3. ed. Brasília: EMBRAPA-SPI, 2013. 353 p.

KELLER, J.; KARMELI, D. Trickle irrigation design. Rain Bird Sprinkler Manufacturing Corporation, Glendora, California, 1975. 135 p.

LIMA, P. A.; MONTENEGRO, A. A. A.; LIRA JUNIOR, M. D. A.; SANTOS, F. X.; PEDROSA, E. M. R. Efeito do manejo da irrigação com água moderadamente salina na produção de pimentão. Revista Brasileira de Ciências Agrárias (Agrária) Brazilian Journal of Agricultural Sciences, v.1, n. 1, p. 73-80, out - dez., 2006.

LIMA, E. M. C.; MATIOLLI, W.; THEBALDI, M. S.; REZENDE, F. C.; FARIA, M. A. Produção de pimentão cultivado em ambiente protegido e submetido a diferentes lâminas de irrigação. Revista Agrotecnologia, v.3, n.1, p. 40-56, 2012.

PEREIRA, A. R.; VILLA NOVA, N. A.; SEDIYAMA, G. C. Evapotranspiração. Piracicaba: FEALQ, 1997. 183 p.

SANTOS, C. S.; SANTOS, D. P.; OLIVEIRA, W. J.; SILVA, P. F.; SANTOS, M. A. L; FONTENELE, A. J. P. B. Evapotranspiração de referência e coeficiente de cultivo da pimenteira no Agreste Alagoano. Revista Brasileira de Agricultura Irrigada, v. 10, n. 5, p. 883 - 892, 2016.

SHARMA, H.; SHUKLA, M. K.; BOSLAND, P. W.; STEINER, R. Soil moisture sensor calibration, actual 
evapotranspiration, and crop coefficients for drip irrigated greenhouse chile peppers. Agricultural Water Management, v. 179, p. 81-91, 2017.

SOUZA, A. D.; PEREIRA, J. B. A.; SILVA, L. D. B. D.; GUERRA, J. G. M.; CARVALHO, D. F. D. Evapotranspiração, coeficientes de cultivo e eficiência do uso da água da cultura do pimentão em diferentes sistemas de cultivo. Acta Scientiarum Agronomy, v.33, p. 15-22, 2011.

XAVIER, R. A.; DORNELLAS, P. DA C. Análise do comportamento das chuvas no município de Arapiraca, região Agreste de Alagoas. GEOGRAFIA (Londrina), v.14, p. 49-64, 